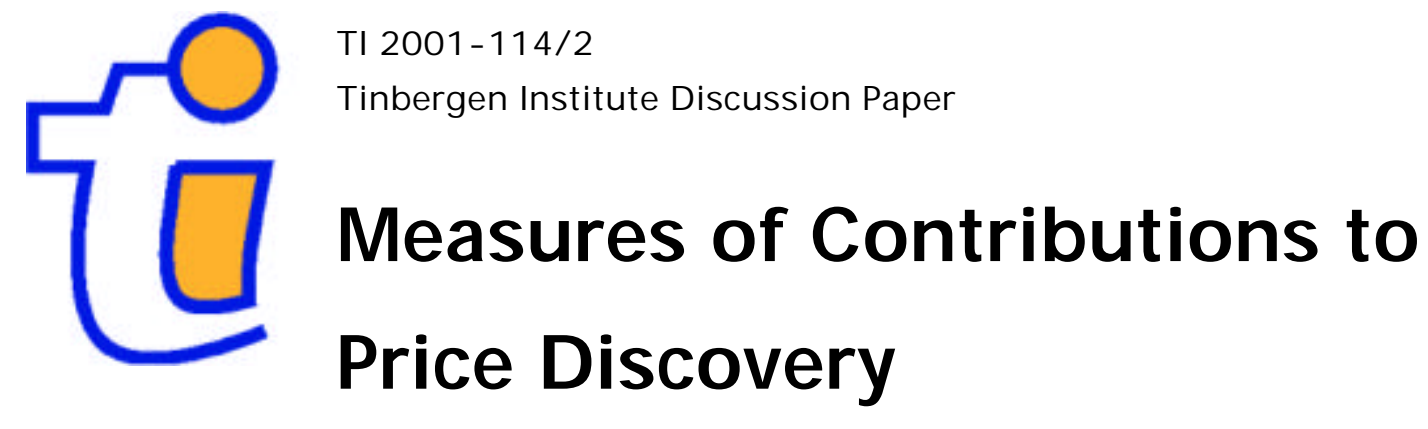

Frank de Jong

Financial Group, Faculty of Economics and Econometrics, University of Amsterdam, and Tinbergen Institute 
Tinbergen Institute

The Tinbergen Institute is the institute for economic research of the Erasmus Universiteit Rotterdam, Universiteit van Amsterdam and

Vrije Universiteit Amsterdam.

Tinbergen I nstitute Amsterdam

Keizersgracht 482

1017 EG Amsterdam

The Netherlands

Tel.: +31.(0)20.5513500

Fax: $\quad+31 .(0) 20.5513555$

Tinbergen Institute Rotterdam

Burg. Oudlaan 50

3062 PA Rotterdam

The Netherlands

Tel.: $\quad+31 .(0) 10.4088900$

Fax: $\quad+31 .(0) 10.4089031$

Most TI discussion papers can be downloaded at

http://www.tinbergen.nl 


\title{
Measures of contributions to price discovery: a comparison *
}

\author{
Frank de Jong \\ University of Amsterdam \\ January 12, 2001
}

\begin{abstract}
This note clarifies the relation between two competing definitions of the contribution to price discovery in market microstructure models: (i) the information share and (ii) the common factor component weight. It is demonstrated that the two measures are closely related, but that only the information share takes into account the variability of the innovations in each market's price.
\end{abstract}

Keywords: Price discovery, Cointegration, Permanent-Transitory decomposition JEL codes:

${ }^{*}$ I thank Joel Hasbrouck for his comments on an earlier draft of this note. Please address correspondence to: Frank de Jong, Finance Group, University of Amsterdam, Roetersstraat 11, 1018 WB, Amsterdam, the Netherlands. phone: +31-20-5255815, fax: +31-20-5255285, e-mail: fdejong@fee.uva.nl 
This note attempts to clarify the relation between two competing definitions of the contribution to price discovery in market microstructure models: (i) the information shares as defined in Hasbrouck (1995) and (ii) the common factor component weight of Gonzalo and Granger (1995), applied in the market microstructure literature by Booth, So and Tse (1999), Chu, Hsieh and Tse (1999) and Harris, McInish and Wood (2000).

Let $X_{t}$ be the vector of prices for the same security in $n$ markets. Each individual price series $x_{i t}$ is non-stationary, but because of long run arbitrage, the series will be cointegrated. The multivariate price process is given by the vector error correction model

$$
\Delta X_{t}=\gamma z_{t}+A_{1} \Delta X_{t-1}+. .+\epsilon_{t}
$$

where $z_{t}=\alpha^{\prime} X_{t}$ are the stationary error correction terms.

There are several ways to decompose the price vector in a permanent, I(1), component and a transitory, $\mathrm{I}(0)$, component. The traditional decomposition is the Stock and Watson (1988) decomposition where the permanent component is a random walk with serially uncorrelated increments. This decomposition works from the Vector Moving Average representation of the model

$$
X_{t}=\epsilon_{t}+C_{1} \epsilon_{t-1}+C_{2} \epsilon_{t-2}+. .=C(L) \epsilon_{t}
$$

which can be written as

$$
X_{t}=C(1) \sum_{s=0}^{t} \epsilon_{s}+C^{*}(L) \epsilon_{t}
$$

If the vector $X_{t}$ is cointegrated, the Granger Represention Theorem (Engle and Granger, 1987) states that $C(1)$ satisfies the properties $\alpha^{\prime} C(1)=0$ and $C(1) \gamma=0$. Thus, we may write

$$
X_{t}=\alpha_{\perp} \theta^{\prime} \sum_{s=0}^{t} \epsilon_{s}+C^{*}(L) \epsilon_{t}
$$

with $\alpha_{\perp}^{\prime} \alpha=0$ and $\theta^{\prime} \gamma=0$. The term $\theta^{\prime} \sum_{s=0}^{t} \epsilon_{s}$ is the common stochastic trend component. The common trend innovations, $\theta^{\prime} \epsilon_{t}$ are serially uncorrelated by construction. Notice that this common trend is defined as a function of the innovations $\epsilon_{t}$ and therefore involves current as well as lagged values of $X_{t}$.

Gonzalo and Granger (1995) propose an alternative decomposition of $X_{t}$ in permanent and transitory components, where the components are linear combinations of $X_{t}$ alone, and do not involve lagged values of $X_{t}$ :

$$
X_{t}=A_{1} f_{t}+A_{2} z_{t}
$$


with $f_{t}=\beta^{\prime} X_{t}$ and $z_{t}=\alpha^{\prime} X_{t}$ as before. As an additional identifying assumption, GG assume that there is no long run Granger causality from $z_{t}$ to $f_{t}$. It turns out that this assumption implies for the permanent component $A_{1} f_{t}=\alpha_{\perp} f_{t}$ and

$$
f_{t}=\beta^{\prime} X_{t}=\left(\gamma_{\perp}^{\prime} \alpha_{\perp}\right)^{-1} \gamma_{\perp}^{\prime} X_{t}
$$

with $\gamma_{\perp}^{\prime} \gamma=0$ and hence $\beta^{\prime} \gamma=0$. This definition of the common factor is different from the Stock-Watson definition because the changes in $f_{t}$ are serially correlated.

How are the decompositions related? An instructive way to look at this issue is by substituting the Stock-Watson decomposition of $X_{t}$ into the Gonzalo-Granger definition of the common factors $f_{t}$ :

$$
\begin{aligned}
f_{t} & =\left(\gamma_{\perp}^{\prime} \alpha_{\perp}\right)^{-1} \gamma_{\perp}^{\prime} X_{t} \\
& =\left(\gamma_{\perp}^{\prime} \alpha_{\perp}\right)^{-1} \gamma_{\perp}^{\prime}\left\{\alpha_{\perp} \theta^{\prime} \sum_{s=0}^{t} \epsilon_{s}+C^{*}(L) \epsilon_{t}\right\} \\
& =\theta^{\prime} \sum_{s=0}^{t} \epsilon_{s}+s_{t}
\end{aligned}
$$

where $s_{t}$ is stationary. So, we see that the random walk part of the GG common factor $f_{t}$ is identical to the Stock-Watson common factor (this result is also stated in Proposition 5 of Gonzalo and Granger). ${ }^{1}$ Sharing the same random walk component is however not a very special property, because all linear combinations of the market's prices, and indeed each individual market price, have the same random walk component. $^{2}$

\section{Market microstructure models}

For the applications to market microstructure models, it is natural to assume that the prices share the same, scalar, common non-stationary component. Because of market microstructure frictions, however, there are temporary deviations from the equilibrium price, but these are transient (stationary). Hence, the cointegrating rank of the VECM is $n-1$, and $\gamma$ is an $n \times(n-1)$ matrix. The $n-1$ dimensional vector

\footnotetext{
${ }^{1}$ In both decompositions, the permanent component and the transitory component are mutually correlated at (possibly) all leads and lags. An alternative decomposition is therefore in orthogonal (i.e. cross serially uncorrelated) permanent and transitory components. These decompositions will not be considered here though.

${ }^{2}$ I thank Joel Hasbrouck for pointing this out.
} 
of error correction terms, $z_{t}$, can be defined in many ways but the simplest definition is

$$
z_{t}=\left(\begin{array}{c}
x_{1 t}-x_{n t} \\
\mid \\
x_{n-1, t}-x_{n t}
\end{array}\right)
$$

I shall use this definition in the remainder of this note. With this definition, $\alpha_{\perp}=\iota$, an $n \times 1$ vector of ones. The Stock-Watson decomposition then becomes

$$
X_{t}=\iota \theta^{\prime} \sum_{s=0}^{t} \epsilon_{s}+C^{*}(L) \epsilon_{t}
$$

where $\theta$ is a $n \times 1$ vector that satisfies $\theta^{\prime} \gamma=0$. Hasbrouck (1995) suggests to use the variance of $\theta_{i} \epsilon_{i t}$, scaled by the total variance of the common trend innovations $\theta^{\prime} \epsilon_{t}$ as a measure of the contribution to price discovery of market $i$. He calls this the information share of market $i$. If there is correlation between the elements of $\epsilon_{t}$, the information shares are not uniquely defined but one can define a range for the information share. This measure of the contribution to price discovery has been applied in many empirical microstructure studies.

The Gonzalo-Granger decomposition in market microstructure models is

$$
f_{t}=\beta^{\prime} X_{t}=\left(\gamma_{\perp}^{\prime} \iota\right)^{-1} \gamma_{\perp}^{\prime} X_{t}
$$

where $\beta$ and $\gamma_{\perp}$ are $n \times 1$ vectors, and the elements of $\beta$ add up to one. Booth, So and Tse (1999), Chu, Hsieh and Tse (1999), and Harris, McInish and Wood (HSW, 2000) suggest to use $\beta_{i}$ as a measure of the contribution to price discovery of market $i$.

What is the relation between the two definitions? First, notice that in the market microstructure setting, where the cointegrating rank is $n-1$, there are $n-1$ orthogonality conditions $\beta^{\prime} \gamma=0$ and $\theta^{\prime} \gamma=0$. These imply that that the vectors $\beta$ and $\theta$ are equal, except for a scale factor. Since $\beta^{\prime} \iota=1$ by construction, we find that $\beta=\left(\theta^{\prime} \iota\right)^{-1} \theta$. Hence, the information share and the GG common factor weights are closely related. The GG common factor weight is a normalized $\theta_{i}$, whereas the information share is a normalized $\theta_{i}^{2} \sigma_{i}^{2}$. The GG common factor weight measures the impact of $\epsilon_{i}$ on the innovation in the permanent component, whereas the information share measures the contribution of $\epsilon_{i}$ to the total variance of the innovation in the permanent component.

An analogy with the standard linear regression model $y=\beta^{\prime} X+\epsilon$ is useful here: the coefficient $\beta_{i}$ measures the impact of a change in the explanatory variable $X_{i}$, 
whereas the (normalized) product $\beta_{i}^{2} \sigma_{X_{i}}^{2}$ measures the fraction of the variance of $y$ explained by $X_{i}$ (a partial $R^{2}$ ).

\section{Examples}

A few simple examples may clarify these results. In both examples there are two markets. The error correction term is the difference between the prices on each market, $z_{t}=X_{1 t}-X_{2 t}$. For simplicity, there are no further lagged price effects, so $A_{k}=0$ for all $k$. The VECM then is

$$
\left(\begin{array}{c}
\Delta X_{1 t} \\
\Delta X_{2 t}
\end{array}\right)=\left(\begin{array}{l}
\gamma_{1} \\
\gamma_{2}
\end{array}\right) z_{t}+\left(\begin{array}{l}
\epsilon_{1 t} \\
\epsilon_{2 t}
\end{array}\right)
$$

The first example concerns the one-way price discovery hypothesis. Under that hypothesis, only the second market error corrects to the price difference,

$$
\begin{aligned}
\Delta X_{1 t} & =\epsilon_{1 t} \\
\Delta X_{2 t} & =\gamma_{2} z_{t}+\epsilon_{2 t}
\end{aligned}
$$

for some strictly positive $\gamma_{2}$. So, $\gamma=\left(0, \gamma_{2}\right)^{\prime}$ and the orthogonal complement of this vector is $\gamma_{\perp}=\left(\theta_{1}, 0\right)^{\prime}$ for any non-zero $\theta_{1}$. In this case, $\beta=(1,0)^{\prime}$ so that $f_{t}=X_{1 t}$. In the Stock-Watson decomposition, $\theta=\left(\theta_{1}, 0\right)$. Both definitions of the contributions to price discovery give the first market a $100 \%$ information share.

In the second example, the two markets error correct half of the difference between the prices

$$
\begin{aligned}
& \Delta X_{1 t}=-0.5 z_{t}+\epsilon_{1 t} \\
& \Delta X_{2 t}=0.5 z_{t}+\epsilon_{2 t}
\end{aligned}
$$

Hence, $\gamma=(-0.5,0.5)^{\prime}$ and $\theta=\gamma_{\perp}=\left(\theta_{1}, \theta_{1}\right)^{\prime}$ for any non-zero $\theta_{1}$. Hence, the common factor $f_{t}=0.5 X_{1 t}+0.5 X_{2 t}$ is uniquely defined. The GG common factor weight will assign a $50 \%$ contribution to price discovery to each market, whatever the variances of $\epsilon_{i t}$. The information shares depend on the variance of $\epsilon_{i t}$. For example, assuming that the errors are uncorrelated, the information shares are

$$
I S_{i}=\frac{\sigma_{i}^{2}}{\sigma_{1}^{2}+\sigma_{2}^{2}}
$$

with $\sigma_{i}^{2}=\operatorname{Var}\left(\epsilon_{i t}\right)$. The information shares may be larger or smaller than $50 \%$, depending on the error variances. As an extreme case, suppose that $X_{2 t}$ is perfectly predictable from the past, i.e. $\sigma_{2}^{2}=0$. The information share for the second market is zero, but the GG common factor weight is 0.5 . 


\section{Conclusion}

This note showed that there is a very close relation between the two definitions of contribution to price discovery. The coefficients $\beta$ of the GG common factors are just a normalized elements of the vector $\theta$ that defines the Stock-Watson common stochastic trend (Hasbrouck's efficient price). The major difference between the two approaches is the role of the variance of the innovations. The GG definition only works with the 'weight' that the innovation of market $i$ has in the increment of the efficient price $\theta^{\prime} \epsilon_{t}$. This definition ignores the variance of $\epsilon_{i t}$. The information share measures the share in the total variance of the efficient price change $\theta^{\prime} \epsilon_{t}$ contributed by market $i$.

In my view both definitions have their merits. The GG definition is useful if one wants to construct the innovations in the efficient price from the full innovation vector $\epsilon_{t}$. This goes back to the motivation of the Gonzalo and Granger (1995) paper; they are interested in constructing a permanent component that is a simple linear combination of the data $\left(f_{t}=\beta^{\prime} X_{t}\right)$. Since the random walk part of $f_{t}$ is the efficient price, the coefficients $\beta_{i}$ tell how much weight to attach to the innovation (=unpredictable change) in the price from market $i$ in constructing the innovation in the efficient price. Hasbrouck's definition is more concerned with the amount of variation in the prices, and how much of that is explained by the price changes on market $i$. This is a more proper measure of the amount of information generated by each market. 


\section{References}

Booth, G.G., R. So, and Y. Tse (1999) Price discovery in the German equity derivatives markets, Journal of Futures Markets 19, 619-643.

Chu, Q.C., W.G. Hsieh, and Y. Tse (1999) Price discovery on the S\&P 500 index markets: An analysis of spot index, index futures and SPDRs, International Review of Financial Analysis 8, 21-34.

Engle, R.F., and C.W.J. Granger (1987), Co-integration and Error Correction: Representation, Estimation and Testing, Econometrica 35, 251-276.

Gonzalo, J., and C.W.J. Granger (1995) Estimation of common longmemory components in cointegrated systems, Journal of Business 8 Economic Statistics 13:1, 27-36.

Harris, R., T.H. McInish, and R.A. Wood (2000), Security Price Adjustment Across Exchanges: An Investigation of Common Factor Components for Dow Stocks, working paper

Hasbrouck, J. (1995) One security, many markets: Determining the contributions to price discovery, Journal of Finance 50:4, 1175-1199.

Stock, J.H., and M.W. Watson (1988) Testing for Common Trends, Journal of the American Statistical Association 83, 1097-1107. 